\title{
Identification of Aflatoxigenic Fungi and Detection of Their Aflatoxin in Red Chilli (Capsicum annuum) Samples Using Direct Cultural Method and HPLC
}

\author{
Md. Nur Hossain ${ }^{1 *}$, Asma Talukder², Farhana Afroze ${ }^{3}$, Md. Matiur Rahim ${ }^{4}$, Shamima Begum³, \\ Md. Zahurul Haque ${ }^{1}$, Monzur Morshed Ahmed ${ }^{1}$ \\ ${ }^{1}$ Industrial Microbiology Laboratory, Institute of Food Science and Technology (IFST), Bangladesh Council of Scientific and \\ Industrial Research (BCSIR), Dhanmondi, Dhaka, Bangladesh \\ ${ }^{2}$ Department of Genetics and Biotechnology, Noakhali Science and Technology University, Noakhali, Bangladesh \\ ${ }^{3}$ Department of Microbiology, Jagganath University, Dhaka, Bangladesh \\ ${ }^{4}$ Food Toxicology Research Laboratory, Institute of Food Science and Technology (IFST), Bangladesh Council of Scientific and \\ Industrial Research (BCSIR), Dhanmondi, Dhaka, Bangladesh \\ Email: *mnhossain84@gmail.com, *mnhossain84@ifstbcsir.gov.bd
}

How to cite this paper: Hossain, Md.N., Talukder, A., Afroze, F., Rahim, Md.M., Begum, S., Haque, Md.Z. and Ahmed, M.M. (2018) Identification of Aflatoxigenic Fungi and Detection of Their Aflatoxin in Red Chilli (Capsicum annuum) Samples Using Direct Cultural Method and HPLC. Advances in Microbiology, 8, 42-53. https://doi.org/10.4236/aim.2018.81004

Received: November 24, 2017

Accepted: January 28, 2018

Published: January 31, 2018

Copyright $\odot 2018$ by authors and Scientific Research Publishing Inc. This work is licensed under the Creative Commons Attribution International License (CC BY 4.0).

http://creativecommons.org/licenses/by/4.0/

\section{(c) (i) Open Access}

\begin{abstract}
Aflatoxins are the potential lethal toxin produced by Aspergillus sp. important health hazard throughout the world. In this study, 26 Aspergillus sp. have been isolated from 50 samples of red chilli collected throughout the country. These 26 isolates were grown primarily on agar media to identify the aflatoxin producing species. It is possible to distinguish A. flavus strains from other Aspergillus sp. developing orange colour on the reverse of the plates. The Coconut Cream Agar (CCA) is used to detect aflatoxin producer strains having blue fluorescence when exposed to a UV-light. Several other media were used for morphological characteristics of Aspergillus sp. Out of 26 isolates, four isolates were confirmed as Aspergillus sp. These isolates were subjected to cross contamination with freshly ground, sterile maize and after 15 days of incubation the contaminated maize were analyzed by HPLC and found aflatoxin in each of the sample containing $186 \mathrm{ppb}$ (max.). This study was conducted to assay the ability to produce aflatoxins by the Aspergillus spp. isolated from red chilli (Capsicum annuum L. Solanaceae) available throughout the country. The results found in the experiment are much more behind the acceptable limit according to some international standard. As red chilli is a widely used spice in Bangladesh, the proper controlling measures may be taken for controlling the surveillance of aflatoxinic fungi like as use of bio-pesticides, proper drying method and storage conditions.
\end{abstract}




\section{Keywords}

Aflatoxin, Aspergillus, Detection, HPLC, Red Chilli

\section{Introduction}

Chilli (Capsicum annuum L. Solanaceae) is one of the most valuable spices and also important cash crops grown in Bangladesh. It is available in the form of green, dried and powdered. It has become an essential ingredient in Bangladeshi meals as it is typically lightly fried with oil in the initial stages of preparation of the dish [1]. According to the survey of Bangladesh Bureau of Statistics [2], plenty of chillies are being produced in the district of Bogra, Rangpur, Kurigram, Jamalpur, Natore and Jessore. It is an important spice in Bangladesh for its wide uses in cooking as well as nutritional value. It has become an essential ingredient in Bangladeshi meals. Every day billions of people use it as a medicinal herb and ornamental plant [3]. It is also used as an ingredient in industrial products. Chilli is an important source of vitamins such as A, C and E for the world population. They are powerful antioxidant and anti-inflammatory agents containing high amounts of carotenoid. The ascorbic acid (vitamin C) and tocopherol (vitamin E) content in chilli is quite high, which makes it very effective as immune system stimulants and healing agent especially for cellular damage [4]. But a high level of consumption of red chili was demonstrated to be an environmental risk factor as it is highly susceptible to fungal contamination and subsequently mycotoxin formation. Chilli is recognized as significant carrier of microbial contamination, primarily molds and some bacteria [5]. Chilies have been reported as one of the crops with high aflatoxin contamination. Temperature and humidity are the crucial factors that can influence the toxin production before and after harvest of the crop [6]. Delayed harvest, late irrigation, rain and dew during warm periods are associated with increased aflatoxin levels [7]. Improper picking practices and offensive post-harvest processing of the chilies may lead to augmented aflatoxin production. Aflatoxin contamination may also take place due to the mechanical damages, stress conditions or damages by birds, mammal or insects etc. [8].

Aflatoxins are the secondary metabolites and potent carcinogens produced by various species of Aspergillus [9]. Aflatoxins are the most potent carcinogenic toxins and widely studied of all mycotoxins. Aflatoxins frequently contaminate agricultural commodities so that causing serious health hazards to humans and animals, as well as great economic loss. Although aflatoxin-production ability has been detected in various species of the Aspergillus genus, inside and outside the Flavi group, Aspergillus flavus and Aspergillus parasiticus remain the most important and representative aflatoxin producers occurring naturally in food commodities [10]. The identification of Aspergillus Section Flavi has been based on morphological and biochemical characterization. The primary morphological 
diagnostic character for separation of $A$. flavus and A. parasiticus is conidial wall ornamentation. When isolates are grown on Czapek-Dox (CZ) media, colonies of $A$. flavus are yellow-green and those of $A$. parasiticus have a distinctly darker green [11] [12].

Several types of aflatoxins are produced in nature belonging to a group called the difuranocoumarins, only four, aflatoxin $\mathrm{B} 1$ (AFB1), aflatoxin $\mathrm{B} 2$ (AFB2), aflatoxin G1 (AFG1), and aflatoxin G2 (AFG2).These toxins are highly carcinogenic and elicit a wide spectrum of toxic effects when foods and feeds contaminated with aflatoxins are ingested. Aflatoxin may alleviate the riskof different diseases including liver cancer, cirrhosis, gastritis etc. Furthermore, the International Agency for Research on Cancer (IARC) acknowledges that there is sufficient evidence in humans for the carcinogrnecity of naturally occuring AFB1 and mixtures of aflatoxins [13] with a role in the etiology of liver cancer. AFB1 is the most potent of all aflatoxins known to date and is generally found in the highest concentration in food and animal feeds [14]. As per the recently introduced European Union (EU) regulations, only $5 \mu \mathrm{g}$ per kg of aflatoxin B1 and 10 $\mu \mathrm{g}$ per kg of total aflatoxins are allowed in chilli [15].

Aflatoxin biosynthesis pathway involves at least 23 enzymatic reactions and almost 15 structurally well-defined aflatoxin intermediates have been identified in aflatoxin biosynthesis $4-6$. Totally 25 identified genes involved in aflatoxin biosynthesis are clustered within a 70-kb DNA region in the chromosome [16]. However, nowadays polymerase chain reaction (PCR), have been developed for testing the presence of pathogens, as well as for confirmation and genotyping of isolates from samples. The biosynthetic pathway for aflatoxin production by $A$. flavus has been elucidated, and genes in the aflatoxin biosynthetic pathway have been identified [17]. The AflR gene plays an important role in the aflatoxin biosynthetic pathway by regulating the activity of other structural genes such as omt- $A$, ver-1, and nor-1. More recently, aflatoxin production and aflatoxigenic strains differentiation are being assessed by monitoring the expression of aflatoxin genes using the reverse transcription polymerase chain reaction (RT-PCR) and real-time PCR methodologies. Such systems have been applied to monitor aflatoxin production and aflatoxin gene expression based on various regulatory and structural aflatoxin pathway genes in Aspergillus parasiticus and/or Aspergillus flavus and were found to be very rapid and sensitive [18].

Conventional methods used for the detection of aflatoxins are microbiological identification, high performance liquid chromatography (HPLC), thin layer chromatography (TLC) or enzyme-linked immune sorbent assay (ELISA) [19]. New instrumental techniques approaches for aflatoxin determination such as fluorescence polarisation, multiphoton-excited fluorescence, LC separation, electrospray ionisation-MS-MS, liquid chromatography-electrospray ionization/ multi-stage mass spectrometry (LC/ESI-MS-MS) detection [20] were developed but all these alternative methods are not always available or affordable to developing countries [21]. High-performance liquid chromatography (HPLC) of ex- 
tracts of commodities, foods and feeds is the most prevalent and sensitive current method for the identification and quantization of mycotoxins. The detection of concentration of the fluorescent mycotoxins AFB2, AFB2, AFG2, AFG2 can be achieved by careful preparation of extracts of grain/fruit samples by HPLC [22]. The study was designed to isolate and identify aflatoxigenic fungi and aflatoxin from red chilli sample throughout the country Direct Visual Cultural Method and using high-performance liquid chromatography (HPLC).

\section{Materials and Methods}

\subsection{Collection of Samples}

A total of 50 chilli samples ( $250 \mathrm{gm}$ each) were collected from different districts of Bangladesh for this study. Samples were brought to the laboratory and stored at $4^{\circ} \mathrm{C}$ until being used [23].

\subsection{Isolation and Screening of Aflatoxicogenic Fungi from the Chilli Samples}

$25 \mathrm{gm}$ of chillies from each sample were dissolved in $225 \mathrm{ml}$ of ringer solution separately and each sample was serially diluted up to $10^{-6}$ by vortexing. Aspergillus differentiation agar (AFPA) medium which is a selective identification medium for the isolation of Aspergillus group strains [24] was then inoculated with $0.1 \mathrm{ml}$ of each dilution for the screening of strains of Aspergillus which are the dominant aflatoxigenic fungi by using spread plate technique incubating at $25^{\circ} \mathrm{C}$ for 7 days. Development of a yellowish orange color of the colonies at the reverse side of the plate indicates the presence of Aspergillus flavus whereas green colored colonies indicate the presence of Aspergillus parasiticus [25]. All isolates were maintained in $20 \%$ glycerol at $-20^{\circ} \mathrm{C}$ and grown on Malt Extract Agar (MEA: Malt 20 g/L, Glucose 20 g/L, Peptone 1 g/L, Agar $20 \mathrm{~g} / \mathrm{L}$ ) in the dark for 7 days at $25^{\circ} \mathrm{C}$ whenever needed for further studies [26].

\subsection{Aflatoxin Producing Isolates in Different Culture Media and Detection with Fluorescence}

Different media were used for growing of aflatoxigenic Aspergillus spp. These include Czapek dox agar medium, Coconut Cream agar (CCA) medium, Malt extract agar (MEA) medium, Rose Bengal Chloramphenicol agar medium and Potato Dextrose Agar (PDA) medium. However, the toxin production in these media varies with extraneous factors such as $\mathrm{pH}$, temperature and time. Incubation for a period of five days is necessary for toxin production. All the isolates were kept at $25^{\circ} \mathrm{C}$ for $5-7$ days. In case of culturing with Coconut Cream agar (CCA) medium, the plates were incubated at $25^{\circ} \mathrm{C}$ for 4 days in the dark, and the presence or absence of fluorescence on the agar surrounding the growing Aspergillus colonies was determined by exposing the Petri dishes to ultraviolet (UV) light (365 nm) and expressed as positive or negative [27]. 


\subsection{Detection of Aflatoxin in Wheat and Maize}

The aflatoxin producing ability of the isolates was tested by inoculating isolated strain in uninfected wheat and maize as these are mostly consumed cereal grains in Bangladesh. First the uninfected maize and wheat were disinfected by autoclaving in a flask and then manually inoculated with isolated Aspergillus spp. strains. Then the conical flasks were kept at room temperature for 15 days. The infected wheat and maize were carried out for the detection of aflatoxin by HPLC.

\subsection{Determination of Aflatoxin Level by High-Performance Liquid Chromatography (HPLC)}

\subsubsection{Sample Preparation}

Extraction was carried out according to extraction method taking 50 gram sample by making slurry with water at 1:2 ratio of sample: water. An appropriate volume of acetone was added to produce acetone to water ratio 1:4 and shaked in a mechanical shaker for 30 minutes and then collected the filtrate through a Whatman no. 1 filter paper in a conical flask. $10 \mathrm{ml}$ methanol and $1 \mathrm{ml}$ lead acetate was added to $10 \mathrm{ml}$ of the filtrate in a $250 \mathrm{ml}$ measuring cylinder and was made up to $150 \mathrm{ml}$ with distilled water [28].

\subsubsection{Clean up}

Clean up was done using SPE Cartridge- $3 \mathrm{ml}, 500 \mathrm{mg}$ PH packing was attached to $75 \mathrm{ml}$ reservoir and a vacuum manifold. The cartridge was conditioned by passing of $15 \mathrm{ml}$ methanol followed by $15 \mathrm{ml}$ water under vacuum after adding 1 gram methanol washed celite. Then $150 \mathrm{ml}$ prepared sample solution was passed through cartridge under vacuum at the rate of $10 \mathrm{ml} / \mathrm{min}$. The cartridge was then washed with $10 \mathrm{ml}$ of water. Any remaining water from the cartridge was removed by the passage of air for about 5 minutes. The $75 \mathrm{ml}$ reservoir was replaced with a $25 \mathrm{ml}$ reservoir and successively another reservoir (4 ml) containing anhydrous sodium sulphate $(500 \mathrm{mg}$ ) and inserted between the cartridge and vacuum manifold. The aflatoxins were eluted using $4 \mathrm{ml}$ of chloroform at the rate of $0.5 \mathrm{ml} / \mathrm{min}$ in a $7 \mathrm{ml}$ vial. The vial was dried under the stream of nitrogen at $45^{\circ} \mathrm{C}$ in a sample concentrator and reconstituted with $1 \mathrm{ml}$ methanol and water (1:1) for HPLC analysis.

\subsubsection{Sample Analysis}

Samples were analyzed using HPLC system-Agilent: Liquid chromatography consist of Agilent: Solvent delivery system (pumps) Series 1100, Agilent series 1100 Column oven Agilent 1200 series Flourosence detector, Manual injector and Cobra cell for post column derivatization. Software: Agilent ChemStation. HPLC Column was C18, $250 \mathrm{~mm}(\mathrm{~L}) \times 4.6 \mathrm{~mm}$ (ID) $10 \mu \mathrm{L}$ (Grace). Mobile phase was $630 \mathrm{ml}$ water, $220 \mathrm{ml}$ methanol, $150 \mathrm{ml}$ acetonitrile, $120 \mathrm{uL}$ of concentrated Nitric acid and $100 \mathrm{mg}$ potassium bromide in isocratic mode with $1 \mathrm{ml}$ flow rate. Total run time was 15 Min and Injection volume was $20 \mathrm{uL}$. Colum 
oven temperature was $30^{\circ} \mathrm{C}$ and excitation wavelength $365 \mathrm{~nm}$, emission wavelength $464 \mathrm{~nm}$. Recovery was calculated for aflatoxins (B1, B2, G1 and G2) fortified at $2 \mathrm{ug} / \mathrm{kg}, 10 \mathrm{ug} / \mathrm{kg}, 20 \mathrm{ug} / \mathrm{kg}, 100 \mathrm{ug} / \mathrm{kg}$ and $200 \mathrm{ug} / \mathrm{kg}$ levels using peak area of chromatograms at concentrations ratio 5:1 (B1, G1: B2, G2) of standards and was found $87 \%-92 \%$. Suitable seven point calibration curve was done, preferably on matrix at $0.5,2,10,25,50,100$ and $250 \mathrm{ng} / \mathrm{ml}(\mathrm{ug} / \mathrm{kg}$ ) level. Linear regression was 0.99 . The calibration batch was prepared from the mixed working standard of $1000 \mathrm{ug} / \mathrm{kg}$ in methanol and water (1:1) which was prepared from stock standard of $20 \mathrm{ppm}$ in acetonitrile. A control spiked samples of $2 \mathrm{ug} / \mathrm{kg}, 50$ $\mathrm{ug} / \mathrm{kg}$ and $200 \mathrm{ug} / \mathrm{kg}$ was run after every 10 samples followed by a solvent as blank. The method was validated as per European commission decision (Commission decision, 2002). The limit of detection was $0.5 \mathrm{ug} / \mathrm{kg}$, Decision Limit $(\mathrm{CC} \alpha)$ was $4.34 \mathrm{ug} / \mathrm{kg}$ and Detection Capability (CC $\beta$ ) was $4.64 \mathrm{ug} / \mathrm{kg}$.

\section{Results and Discussion}

\subsection{Morphological Identification of Aflatoxin Producing Aspergillus}

A total number of 26 colonies were got from 50 chilli samples. By culturing the samples in AFPA media (Figure 1(a)), it is possible to distinguish these species from other Aspergillus based on the development of orange color on the reverse of the plates. Four potential isolates were selected in this study. The CCA is used to detect aflatoxin producer strains (Figure 1(b)). When exposed to a UV-light, the production of aflatoxin is detected by a green-blue fluorescence [29]. When grown on CZ, colonies between the two species can also be separated taxonomically (Figure 2(a) \& Figure 2(b)). The yellow-green color producing colonies are regarded as $A$. flavus and darker green color producing colonies are considered as $A$. parasiticus [30]. The aflatoxin-producing isolates were identified by cultivating fungal strains in Czapek dox agar medium for 5 days at $25^{\circ} \mathrm{C}$ [31].

For growing of aflatoxigenic Aspergillus sp. different media were used. The colony morphology of the isolates is summarized at Table 1.

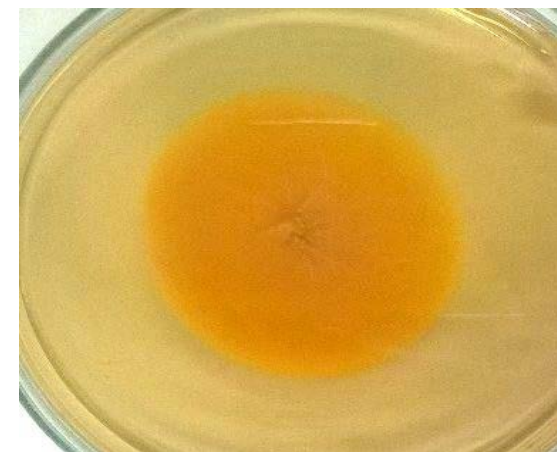

(a)

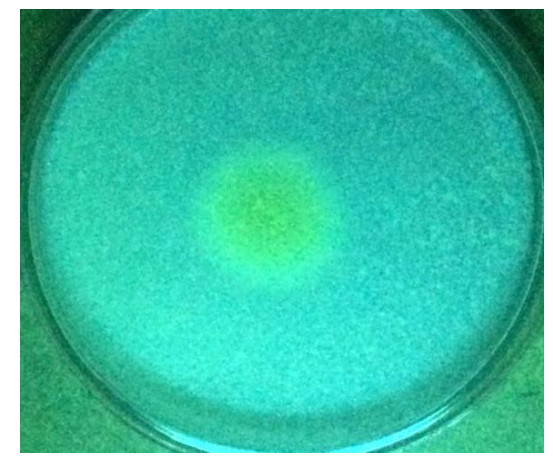

(b)

Figure 1. (a) A. flavus in AFPA, after 7 days incubation at $25^{\circ} \mathrm{C}$, with the characteristic orange color on the reverse side of the plate; (b) Aflatoxigenic A. flavus grown on plates of CCA under long-wave UV light, after 7 days incubation. 


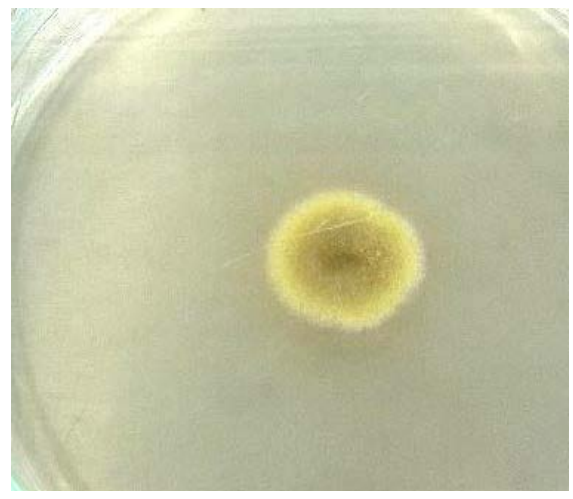

(a)

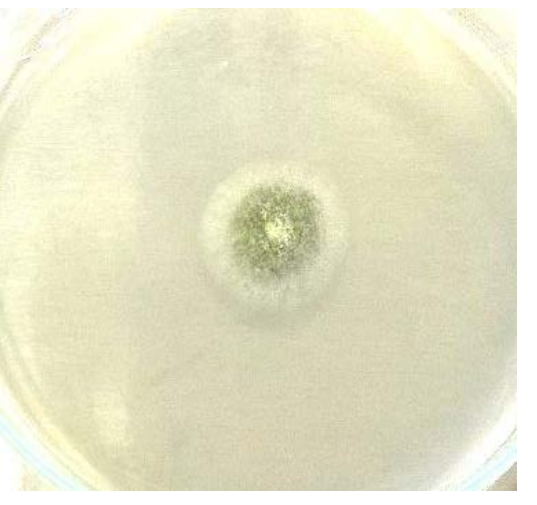

(b)

Figure 2. A. flavus (a) and $A$. parasiticus (b) strains growing on CZ media.

Table 1. Morphological characteristics of aflatoxigenic Aspergillus in different media.

\begin{tabular}{cc}
\hline Name of Media & Colony Morphology \\
\hline Malt Extract Agar (MEA) & Dark green to yellow colony with white edge. \\
Rose Bengal Chloramphenicol Agar Medium & Yellow to green colony with white edge. \\
Sabouraud Dextrose Agar (SDA) & Whitish colony. \\
Potato Dextrose Agar (PDA) & Lime green to yellow colony with white edge \\
Yeast Extract Agar (YEA) & Dark green to yellow colony with white edge.
\end{tabular}

Different types of media were being used for growth and culture preservation but Malt Extract Media (MEM) gave the best possible growth of $A$. flavus strains [32], [33] and [34]. The Rose Bengal chloramphenicol agar medium has been used to isolate $A$. flavus group fungi numerous samples such as nuts, peanuts, corn, cereal, spices and diverse soil samples. This was reported by [35] demonstrated that Sabouraud Dextrose and Yeast Extract agar media was used efficiently to detect aflatoxin producing Aspergillus flavus after 3 days of incubation at $28^{\circ} \mathrm{C}$. He also evaluated that the using of those media at fifth or sixth day of incubation became difficult because mycelial growth reached almost the margin of the Petri dish. Potato dextrose agar is a suitable media for growth of aflatoxin producing Aspergillus flavus [36].

\subsection{Detection of Aflatoxin by HPLC}

Based on the visual culture method and morphological studies, twenty six Aspergillus strains were isolated and purified. The results of visual culture method were confirmed by high performance liquid chromatography (HPLC) method and analysis of aflatoxin production in red chilli samples were shown (Figure 3(a) \& Figure 3(b)) [32].

As the sample collected directly analyzed by HPLC, found max. $68.674 \mathrm{ppb}$ and $12.052 \mathrm{ppb}$ min. Almost $75 \%$ of collected raw sample contain Aflatoxin (G2, G1, B2, B1). All isolates which showed pink/red colour at their reverse had strong signal of AFB1 in their HPLC chromatogram. 

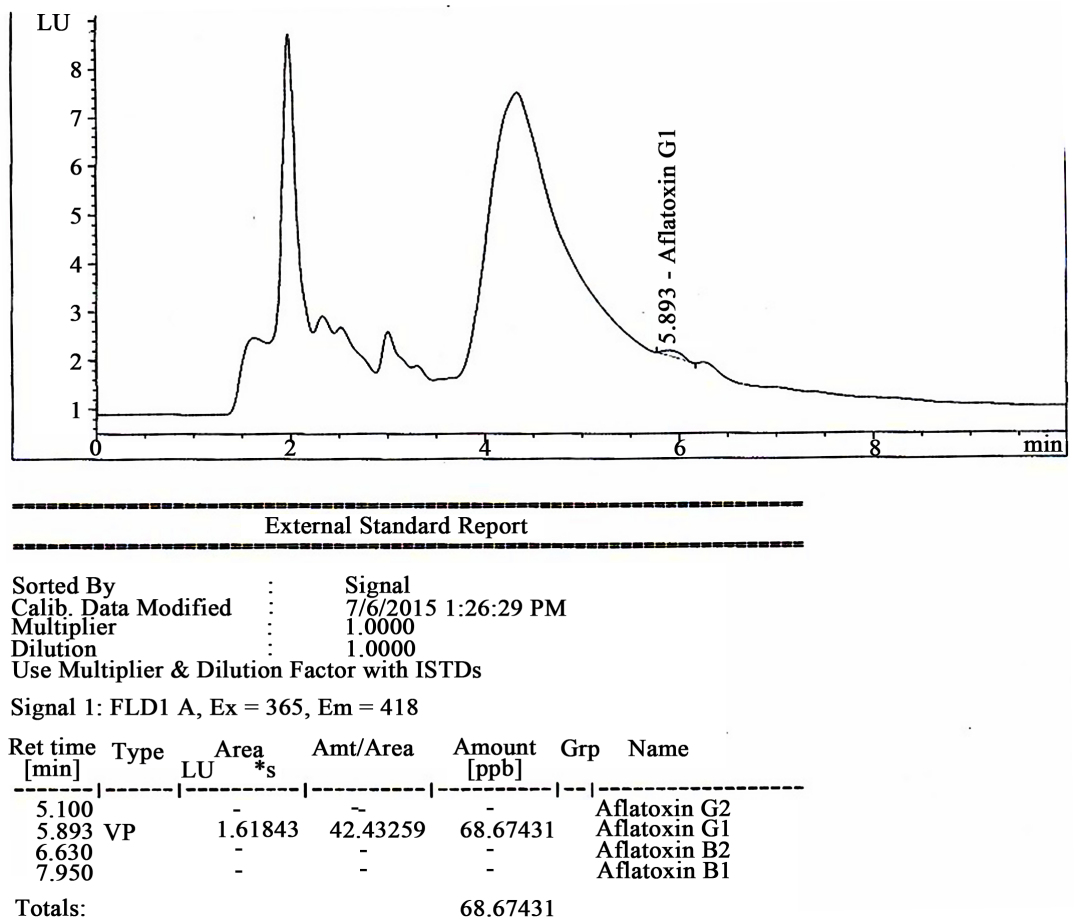

(a)
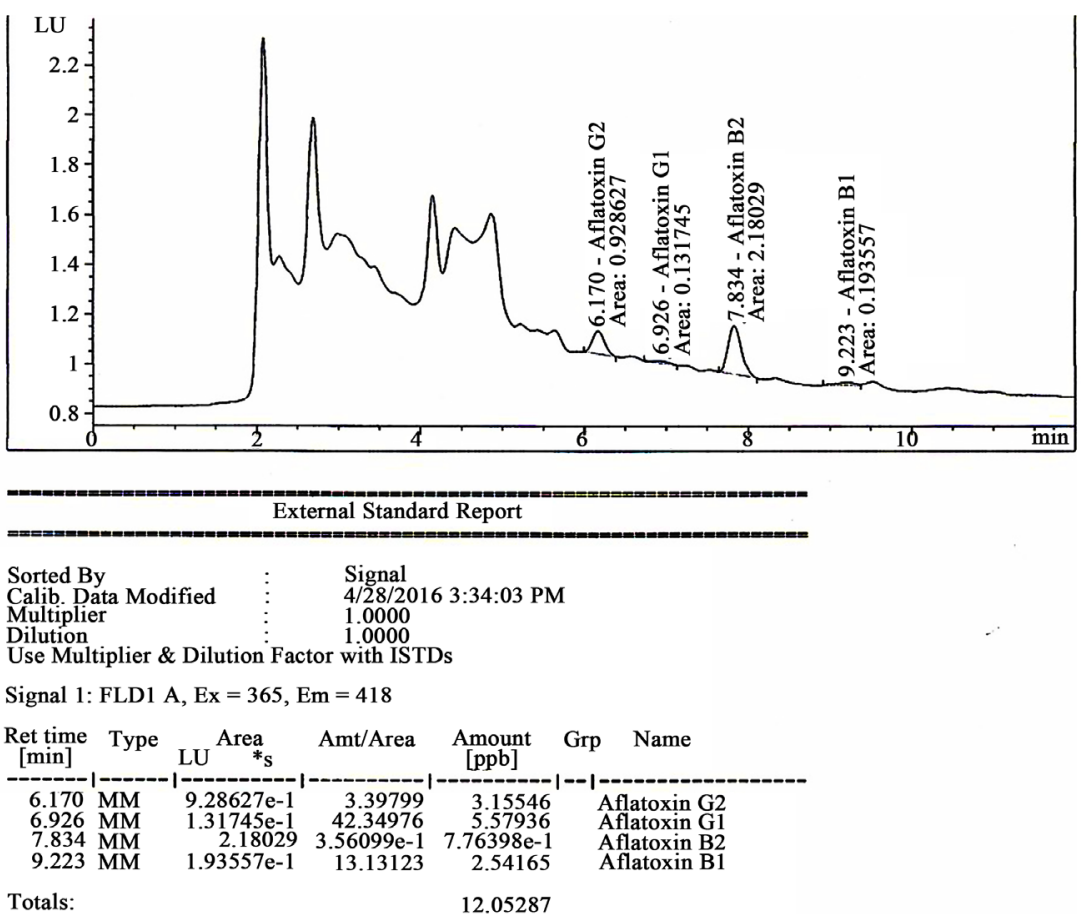

(b)

Figure 3. (a) \& (b) HPLC chromatogram of aflatoxin from red chilli sample.

The cross contaminated samples were analyzed and it is remarkable that max. $186.518 \mathrm{ppb}$ where AFB1 $55.693 \mathrm{ppb}$ and $26.497 \mathrm{ppb}$ min where AFB1 10.226 ppb aflatoxin was found (Figure 4(a) \& Figure 4(b)) [37]. It is noted that the maximum acceptable limit for AFB1 is $2 \mathrm{ppb}$ and $4 \mathrm{ppb}$ for overall aflatoxin 


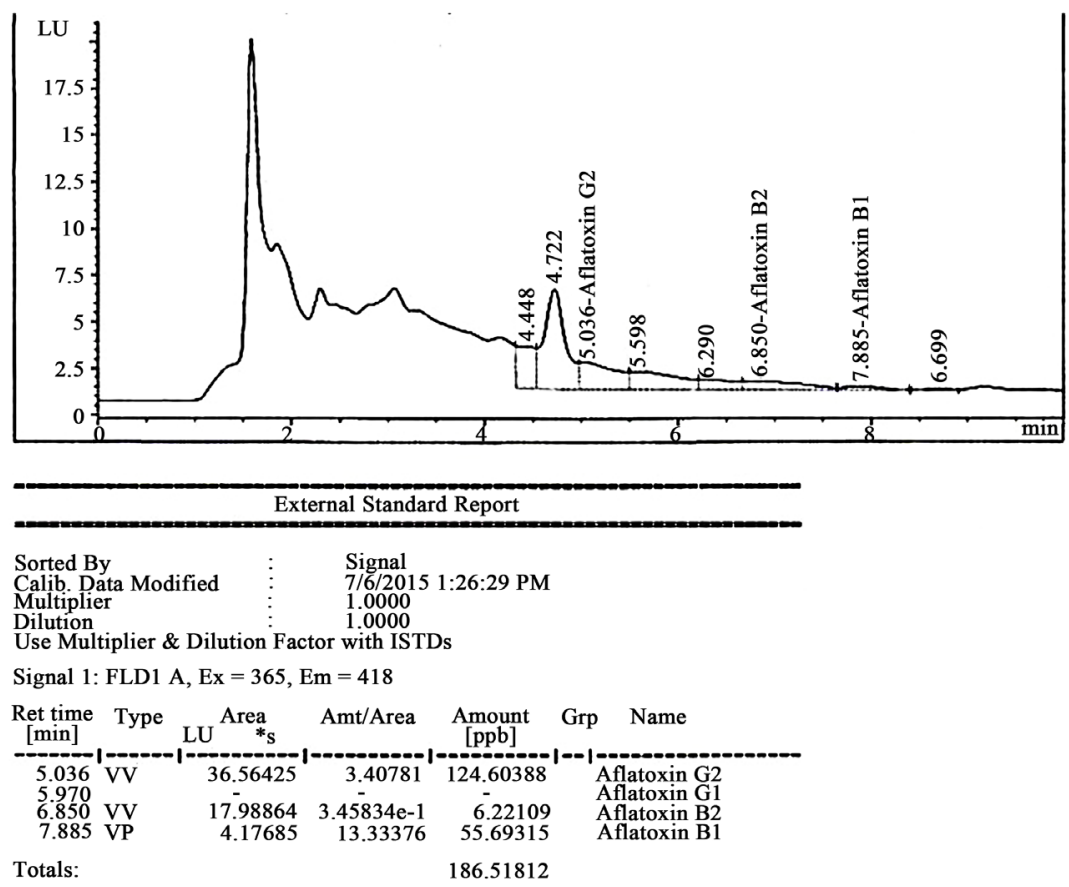

(a)

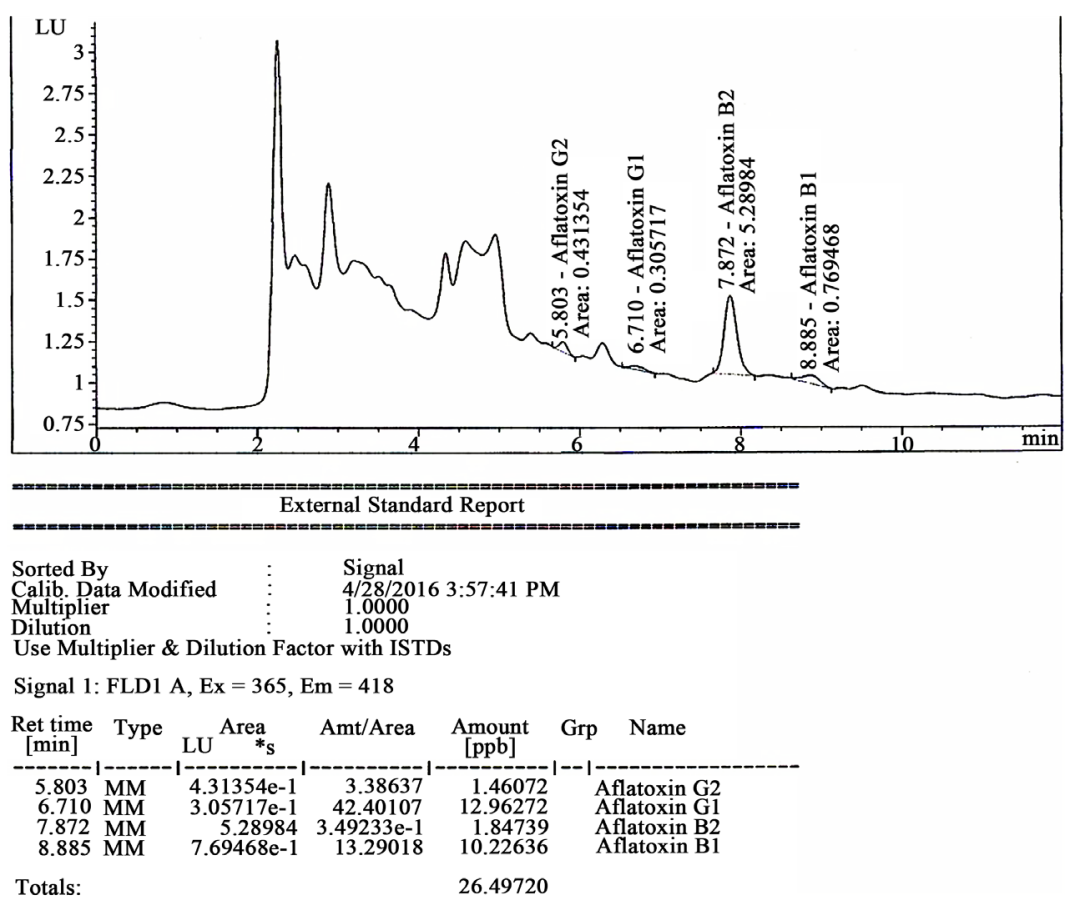

(b)

Figure 4. (a) \& (b) HPLC chromatogram of aflatoxin from cross contaminated sample.

according to European Union standard. In this study, it was observed that most of the dry red chilli available in Bangladesh contaminated with Aspergillus sp. containing a considerable amount of aflatoxin, which is a lethal mycotoxin. Necessary steps should be taken to control the spread-out of aflatoxin producing Aspergillus. 


\section{Conclusion}

This study was conducted to assay the ability to produce aflatoxins by the Aspergillus spp. isolated from red chilli (Capsicum annuum L. Solanaceae) available throughout the country. The results found in the experiment are much more behind the acceptable limit according to some international standard. As red chilli is a widely used spice in Bangladesh for food preparations, contamination of red chilies has both health and economic implications. Thus extensive research need to be done to identify the exact factors responsible for aflatoxin contamination in red chili and proper controlling measures may be taken for controlling the surveillance of aflatoxinic fungi like as use of bio-pesticides, proper drying method and storage conditions. This type of practice may help the chili growers to maintain the required standards quality of their produce and be capable to supply aflatoxin free chili to the processors. Consequently, the availability of safe chili for domestic population and export will be a step forward to combat the food safety issues and to support the economic affairs of Bangladesh.

\section{Acknowledgements}

The authors like to thanks the BCSIR authority as the work is a research and developmental work of BCSIR.

\section{References}

[1] BBS (2014) Bangladesh Bureau of Statistics. Statistical Yearbook of Bangladesh. Ministry of Planning. The Government of the People's Republic of Bangladesh, Dhaka.

[2] BBS (2015) Bangladesh Bureau of Statistics. Statistical Yearbook of Bangladesh. Ministry of Planning. The Government of the People's Republic of Bangladesh, Dhaka.

[3] Rajeev, L. (2010) Peppers: Types of Pepper. http://www.wikipedia.com

[4] Marín, S., Colom, C., Sanchis, V. and Ramos, A.J. (2009) Modeling of Growth of Aflatoxigenic A. flavus Isolates from Red Chili Powder as a Function of Water Availability. International Journal of Food Microbiology, 128, 491-496. https://doi.org/10.1016/j.ijfoodmicro.2008.10.020

[5] Romagnoli, B., Menna, V., Gruppioni. N. and Bergamini, C. (2007) Aflatoxins in Spices, Aromatic Herbs, Herbs-Teas and Medicinal Plants Marketed in Italy. Food Control, 18, 697-701. https://doi.org/10.1016/j.foodcont.2006.02.020

[6] Cotty, P.J. (1991) Effect of Harvest Date on Aflatoxin Contamination of Cotton Seed. Plant Disease, 75, 312-314. https://doi.org/10.1094/PD-75-0312

[7] Cotty, P.J. and Jaime-Garcia, R. (2007) Influences of Climate on Aflatoxin Producing Fungi and Aflatoxin Contamination. International Journal of Food Microbiology, 119, 109-115. https://doi.org/10.1016/j.ijfoodmicro.2007.07.060

[8] Cotty, P.J. and Lee, L.S. (1990) Position and Aflatoxin Levels of Toxin Positive Bolls on Cotton Plants. Proceedings of the Beltwide Cotton Production and Research Conference, National Cotton Council of America, Las Vegas, NV, 34-36.

[9] Ehrlich, K.C., Montalbano, V.G. and Cotty, P.J. (2003) Sequence Comparison of aflR from Different Aspergillus Species Provides Evidence for Variability in Regulation of Aflatoxin Production. Fungal Genetics and Biology, 38, 63-74. 
https://doi.org/10.1016/S1087-1845(02)00509-1

[10] Cary, J.W. and Ehrlich, K.C. (2006) Aflatoxigenicity in Aspergillus. Molecular Genetics, Phylogenetic Relationships and Evolutionary Implications. Mycopathologia, 162, 167-177. https://doi.org/10.1007/s11046-006-0051-8

[11] Klich, M.A. (2002) Identification of Common Aspergillus Species. CBS, Heerlen.

[12] Samson, R.A., Hoekstra, E.S. and Frisvad, J.C. (2004) Introduction to Food and Airborne Fungi. 7th Edition, CBS, Wageningen.

[13] IARC (1993) International Agency for Research on Cancer. Some Naturally Occurring Substances, Food Items and Constituents, Heterocyclic Aromatic Amines and Mycotoxins, Vol. 56, World Health Organization, Lyon, 489-521.

[14] Lee, N.A., Wang, S., Allan, R.D. and Kennedy, I.R. (2004) A Rapid Aflatoxin B1 ELISA: Development and Validation with Reduced Matrix Effects for Peanuts, Corn, Pistachio and Soybeans. Journal of Agricultural and Food Chemistry, 52, 2746-2755. https://doi.org/10.1021/jf0354038

[15] Russell, R. and Paterson, M. (2007) Aflatoxins Contamination in Chilli Samples from Pakistan. Food Control, 18, 817-820. https://doi.org/10.1016/j.foodcont.2006.04.005

[16] Payne, G.E., Nystrum, G.J. and Bhatnagar, B. (1993) Cloning of the afl-2gene Involved in Aflatoxin Biosynthesis from Aspergillus flavus. Applied and Environmental Microbiology, 59, 156-162.

[17] Yu, J., Chang, P.K., Ehrlich, K.C., Cary, J.W., Bhatnagar, D., Cleveland, T.E., Payne, G.A., Linz, J.E., Woloshuk, C.P. and Bennett, J.W. (2004) Clustered Pathway Genes in Aflatoxin Biosynthesis. Applied Environmental Microbiology, 70, 1253-1262. https://doi.org/10.1128/AEM.70.3.1253-1262.2004

[18] Degola, F., Berni, E., Dall'Asta, C., Spotti, E., Marchelli, R., Ferrero, I. and Restivo, F.M. (2007) A Multiplex RT-PCR Approach to Detect Aflatoxigenic Strains of Aspergillus flavus. Journal of Applied Microbiolgy, 103, 409-417. https://doi.org/10.1111/j.1365-2672.2006.03256.x

[19] Shapira, R., Paster, N., Eyal, O., Menasherov, M., Mett, A. and Salomon, R. (1996) Detection of Aflatoxigenic Moulds in Grains by PCR. Applied and Environmental Microbiology, 62, 3270-3273.

[20] Trucksess, M.W. (2003) Committee on Natural Toxins and Food Allergens. General Referee Reports. Journal of AOAC International, 86, 129-138.

[21] Ouattara-Sourabie, P.B., Nikiema, P.A., Barro, N., Savadogo, A. and Traore, A.S. (2012) Aflatoxigenic Potential of Aspergillus spp. Isolated from Groundnut Seeds, in Burkina Faso, West Africa. African Journal of Microbiology Research, 6, 2603-2609.

[22] Nguyen, M.T., Tozlovanu, M., Tran, T.L. and Pfohl-Leszkowicz, A. (2007) Occurrence of Aflatoxin B1, Citrinin and Ochratoxin A in Rice in Five Provinces of the Central Region of Vietnam. Food Chemistry, 205, 42-47.

https://doi.org/10.1016/j.foodchem.2007.03.040

[23] Czerwiecki, L., Czajkowska, D. and Witkowska-Gwiazdowska, A. (2002) On Ochratoxin A and Fungal Flora in Polish Cereals from Conventional and Ecological Farms. Part 2: Occurrence of Ochratoxin A and fungi in Cereals in 1998. Food Additives and Contaminants, 19, 1051-1057. https://doi.org/10.1080/02652030210156313

[24] Pitt, J.I., Hocking, A.D. and Glenn, D.R. (1983) An Improved Medium for the Detection of Aspergillus flavus and A. parasiticus. Journal of Applied Bacteriology, 54, 
109-114. https://doi.org/10.1111/j.1365-2672.1983.tb01307.x

[25] Assante, G., Camrada, L., Locci, R.R., Merlini, L., Nasini, G. and Popadopoulos, E. (1981) Isolation and Structure of Red Pigments from Aspergillus flavus and Related Species, Grown on a Differential Medium. The Journal of Agricultural and Food Chemistry, 29, 785-787. https://doi.org/10.1021/jf00106a023

[26] Rodrigues, P., Venancio, A., Kozakiewicz, Z. and Lima, N. (2009) A Polyphasic Approach to the Identification of Aflatoxigenic and Non-Aflatoxigenic Strains of Aspergillus Section Flavi Isolated from Portuguese Almonds. International Journal of Food Microbiology, 129, 187-193.

https://doi.org/10.1016/j.ijfoodmicro.2008.11.023

[27] Franco, C.M., Fente, C.A., Vazquez, B.I. and Cepeda, A. (1998) Interaction between Cyclodextrins and Aflatoxins $\mathrm{Q}_{1}, \mathrm{M}_{1}$ and $\mathrm{P}_{1}$. Fluorescence and Chromatographic Studies. Journal of Chromatography A, 815, 21-29.

https://doi.org/10.1016/S0021-9673(98)00509-3

[28] Huq, M.S., Amin, M.R., Dawlatana, M., Shahida, S., Rahim, M. and Khan, S.A. (1999) Investigation on the Occurrence of Aflatoxin/Mycotoxin in Food Grains and Feed Stuffs of Bangladesh: Part-I: Aftlatoxin in Rice. Bangladesh Journal of Scientific and Industrial Research, 34, 136-143.

[29] Davis, C.E., Jolley, V.D., Mooso, G.D., Robinson, L.R. and Horrocks, R.D. (1987) Quality of Stockpiled Bigalta Limpograss Forage at Varying Fertility Levels. Agronomy Journal, 79, 229-235. https://doi.org/10.2134/agronj1987.00021962007900020012x

[30] Rodrigues, P., Soares, C., Kozakiewicz, Z., Paterson, R.R.M., Lima, N. and Venâncio, A. (2007) Identification and Characterization of Aspergillus flavus and Aflatoxins. In: Méndez-Villas, A., Ed., Communicating Current Research and Educational Topics and Trends in Applied Microbiology, Formatex, Badajoz, 527-534.

[31] Ben Fredj, S.M., Chebil, S. and Mliki, A. (2009) Isolation and Characterization of Ochratoxin A and Aflatoxin B1 Producing Fungi Infecting Grapevines Cultivated in Tunisia. African Journal of Microbiology Research, 3, 523-527.

[32] Paterson, R. and Lima, N. (2011) Further Mycotoxin Effects from Climate Change. Food Research International, 44, 2555-2566.

https://doi.org/10.1016/j.foodres.2011.05.038

[33] Bokhari, F. and Aly, M.M. (2009) Patulin Production by Penicillium glabrum Isolated from Coffea arabica L. and the Activities of Some Natural Antifungal and Antimycotoxin Plants. Egyptian Journal of Microbiology, 44, 47-59. https://doi.org/10.21608/ejm.2009.285

[34] Hadi, A.M.A., Caley, D.P., Carter, D.R.F. and Magan, N. (2011) Control of Aflatoxin Production of Aspergillus flavus and Aspergillus parasiticus Using RNA Silencing Technology by Targeting aflD (nor-1) Gene. Toxins (Basel), 3, 647-659. https://doi.org/10.3390/toxins3060647

[35] Ordaz, J.J., Fente, B.I., Vazquez, C.M. and Cepeda, A. (2003) Development of a Method for Direct Visual Determination of Aflatoxin Production by Colonies of the Aspergillus flavus Group. International Journal of Food Microbiology, 83, 219-225. https://doi.org/10.1016/S0168-1605(02)00362-8

[36] Fakruddin, M., Chowdhury, A., Hossain, M.N. and Ahmed, M.M. (2016) Characterization of Aflatoxin Producing Aspergillus flavus from Food and Feed Samples. SpringerPlus, 4, 159.

[37] Nakai, V., de Oliveira Rocha, L., Gonçalez, E., Fonseca, H., Ortega, E. and Corrêa, B. (2008) Distribution of Fungi and Aflatoxins in a Stored Peanut Variety. Food Chemistry, 106, 285-290. https://doi.org/10.1016/j.foodchem.2007.05.087 